\title{
Orthorexia nervosa in university athletes
}

\author{
A. Farooq and J. Bradbury \\ School of Applied Sciences, Queensgate, University of Huddersfield, HD1 3DH
}

Orthorexia nervosa is a condition characterised by an obsession with healthy eating ${ }^{(1)}$. Orthorexic individuals pursue their healthy eating obsession by adhering to a strict diet focussing on quality rather than quantity, exhibiting unreasonable concern over food preparation, cooking equipment and following set eating patterns ${ }^{(2)}$. Eventually, diet becomes the most important part of their lives thus obsession is associated with malnourishment, social isolation and poor quality of life ${ }^{(3)}$. Athletes exert a high degree of control over their diets in order to maximise athletic performance, putting them at a greater risk of $\mathrm{ON}^{(4)}$. The level of competition athletes are involved in may be associated with the level of risk to the athlete.

Adherence to the Western social ideal of thinness may also put female athletes at greater risk of $\mathrm{ON}^{(5)}$. No relationship between body mass index (BMI) and ON has been shown in the general population ${ }^{(3)}$; however, this relationship remains unexplored in athletes. Therefore, the aims of this study were to measure $\mathrm{ON}$ in athletes, to compare $\mathrm{ON}$ by gender and competition level, and to explore the relationship with BMI.

University students (aged $\geqslant 18$ years, female and male) who either represented their university competitively in sport or participated for leisure purposes were recruited between November 2015 and February 2016. Participants completed paper-based questionnaires either at the beginning or end of a training session. A validated measure (orthorexia nervosa assessment scale, ORTO-15) ${ }^{(1)}$ was used to assess $\mathrm{ON}$; information on gender, competition level $\left(1^{\text {st }}\right.$ team $/ 2^{\text {nd }}$ team/leisure $)$, and self-reported weight and height were also collected. ORTO-15 consists of 15 items, scored 1 to 4, with a low score indicating higher levels of ON. A score <35, which has shown high specificity for diagnosis purposes ${ }^{(4)}$, was chosen as the threshold for classifying individuals as having ON. The score for ORTO-15 was not normally distributed, therefore median and interquartile range (IQR) are reported and non-parametric statistical tests conducted.

Of the 228 athletes that completed questionnaires, complete data were available for 213, $84(39 \%)$ females and 129 (61\%) males, with a median (IQR) age of $20(2)$ years. The majority $(172,81 \%)$ were in the $1^{\text {st }}$ team, $10(5 \%)$ played for the $2^{\text {nd }}$ team, and the remainder $(31,15 \%)$ were leisure participants. Median BMI was $24.3 \mathrm{~kg} / \mathrm{m}^{2}\left(5.7 \mathrm{~kg} / \mathrm{m}^{2}\right)\left[\mathrm{females} 23 \cdot 3 \mathrm{~kg} / \mathrm{m}^{2}\left(5 \cdot 0 \mathrm{~kg} / \mathrm{m}^{2}\right), \mathrm{males}\right.$ $\left.25.1 \mathrm{~kg} / \mathrm{m}^{2}\left(5.5 \mathrm{~kg} / \mathrm{m}^{2}\right), p=0.002\right]$. The median score for ORTO-15 was $36(10)$, with no difference in score between females and males (see table). ORTO-15 score was not significantly different by competition level. Based on a score of $<35,37 \%(n=79)$ were diagnosed as having ON, $31 \%(n=26)$ of females and $41 \%(n=53)$ of males, $p=0 \cdot 177$. Thirty-six percent $(n=62)$ of $1^{\text {st }}$ team players, $30 \%(n=3)$ of $2^{\text {nd }}$ team players, and $45 \%(n=14)$ of leisure participants were diagnosed as having ON $(p=0 \cdot 56)$. There was no relationship between BMI and ORTO-15 $(r=0.033, p=0.653)$.

\begin{tabular}{|c|c|c|c|c|c|c|c|}
\hline & $\begin{array}{c}\text { Females } \\
\text { Median (IQR) }\end{array}$ & $\begin{array}{c}\text { Males } \\
\text { Median (IQR) }\end{array}$ & $\mathrm{P}$ & $\begin{array}{c}1^{\text {st }} \text { Team } \\
\text { Median (IQR) }\end{array}$ & $\begin{array}{c}2^{\text {nd }} \text { Team } \\
\text { Median (IQR) }\end{array}$ & $\begin{array}{c}\text { Leisure } \\
\text { Median (IQR) }\end{array}$ & $\mathrm{P}$ \\
\hline ORTO-15 score & $37(9)$ & $36(11)$ & $0 \cdot 209$ & $37(10)$ & $39(12)$ & $36(12)$ & 0.078 \\
\hline
\end{tabular}

The findings agree with the limited European athlete studies conducted which suggest athletes are susceptible to ON behaviour ${ }^{(4)}$. To date, this is the first study conducted in a United Kingdom (U.K.) university athletes sample which has revealed a higher frequency of $\mathrm{ON}$ than previously observed in athletes ${ }^{(4)}$. Future qualitative research could be conducted among ON individuals to investigate attitudes and opinions to their eating behaviours.

1. Donini ML, Marsili D, Graziani PM et al. (2005) Eat Weight Disord 10, 28-32.

2. Varga M, Thege BK, Dukay-Szabó S et al. (2014) BMC Psychiatry 14, 59-59.

3. Varga M, Thege BK, Dukay-Szabó S et al. (2013) Eat Weight Disord 18, 103-111.

4. Segura-García C, Papaianni MC, Caglioti F et al. (2012) Eat Weight Disord 17, 226-233.

5. Eriksson L, Baigi A, Markland B et al. (2008) Scand J Med Sci Sports 18, 389-394. 